dry climate, in early graves, to control the interpretation of the vividly pictorial art of the contemporary potters, not only as to the decoration of the clothing, but even as to its shapes and construction. The modelled and painted Chicama pottery is naturally the most eloquent, but the modelled black-ware from the Lambayeque and Trujillo districts contributes much interesting detail. Headgear, head-ornaments, and hairdressing are, of course, included in the survey; and the difficult question (p. 92) whether tattooing coexisted with face-painting is settled by Dr. Folke Henschen's examination of a piece of mummified skin, which shows dead black "exogenous pigmentation, arisen during life, that is to say, the result of tattooing ", though he has not been able to identify the pigment chemically. Its resemblance to coal-dust pigment, in the human lung, supports the obvious guess that soot was used.

For the Inca period, and especially for the culture of the Inca-folk themselves, the evidence is different. The damp climate of the Andes has wrecked most of the original garments, and apparently the pottery does not clearly distinguish between pre-Incan costume and Incan. But the Spanish descriptions, referring, as they do, to the higher ranks of society mainly, and consequently reproducing Inca habits, supply the deficiency of archæological material. Especially valuable, both for garments and for textile processes, are the naïve sketches in Huaman Poma de Ayala's manuscript. Another curious source of evidence is in the myths which describe the divine institution of certain venerable and unalterable costumes; and it is probable that this conservatism, as well as the skilled workmanship noted on p. 195, explains the "surprising consistency in the measurements of Inca shirts found in graves in the highlands, where more clothing was worn and conditions were more favourable for its preservation".

Numerous excellent illustrations and a full bibliography add greatly to the usefulness of this careful and well-written memoir.

\section{Species-Hybrids in Plants.}

Artbastarde bei Pflanzen. Von O. Renner. (Handbuch der Vererbungswissenschaft, herausgegeben von E. Baur und M. Hartmann, Lieferung 7, Band 2.) Pp. iv +161 . (Berlin: Gebrüder Borntraeger, 1929.) 28 gold marks.

rTHE eighteenth-century hybridisers-Kölreuter, Knight, Sageret, Gärtner-studied almost exclusively interspecific crosses, although Sageret, like
Mendel, gave his attention to pairs of contrasted characters. This method of choosing the most complicated rather then the simplest cases in investigating the laws of heredity continued largely in vogue, with the great exception of Mendel, until near the end of the nineteenth century, and retarded for at least half a century the understanding of these laws. Following the rediscovery of the Mendelian analysis, investigators for many years dealt with variety differences, mainly in domesticated plants and animals. But with elucidation of the Mendelian principles, research on species-hybrids soon began again in such work as that of Baur on Antirrhinum and of East on Nicotiana. Later genetical work has drifted more and more into the investigation of genera by crossing and cytological study of their species.

This application of the Mendelian weapon to the more complicated problems of specific structure and relationship, in conjunction with chromosome study, together with taxonomic and distributional treatment, is one of the newer and most promising lines of development in genetics. Such studies have already led to important results, and are bringing us to new points of view in phylogeny and evolution.

Prof. Renner has done a valuable service to biology in summarising this recent genetical work on species-hybrids in plants. The first section of his book deals with the $F_{1}$ phenotypes, including intermediate hybrids, cases of unlike reciprocal hybrids (especially in Enothera, Epilobium, and Digitalis), multiformity and vegetative segregation in the first generation. The structure of the pollen, the chromatophores and the chromosomes of such hybrids is discussed, as well as questions of hybrid vigour (heterosis), dwarfing, new formations, and sterility in these forms.

In another section the methods of reproduction and the offspring of species-hybrids are considered at length, including their chromosome behaviour during meiosis. A short chapter is concerned with the cases, mostly quite recent, where a constant hybrid has been produced through a doubling in its chromosomes. Here are cited Enothera gigas and Primula kewensis, as well as cases in Rosa, Nicotiana, Asgilops-Triticum, Raphanus-Brassica, Papaver, Crepis, etc.

A final page only is devoted to species-crossing in Nature. This section could have been profitably much extended, but perhaps deserves separate treatment. Following the extensive bibliography there is unfortunately no index.

\section{R. Ruggles Gates.}

